\title{
Anatomical And Radiological Study of Superior Orbital Fissure
}

Ajay Kumar PATEL ${ }^{a}$, Alok TRIPATHI ${ }^{b}$, Rajesh KUMAR ${ }^{c}$, Rashmi Bala PATEL ${ }^{d}$

aDepartment Of Anatomy, All India Institute of Medical Sciences, Deoghar, Jharkhand, India

bDepartment of Anatomy, Subharti Medical College,

Swami Vivekanand Subharti University, Meerut, Uttar Pradesh, India

'Department of Forensic Medicine, All India Institute of Medical Sciences, Deoghar, Jharkhand, India

dDepartment of Obstetrics and Gynecology, All India Institute of Medical Sciences, Deoghar, Jharkhand, India

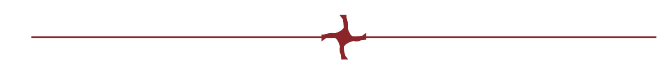

\begin{abstract}
-
Introduction: Superior orbital fissure (SOF) is a very important region through which important nerves and vessels of the orbit pass. Comprehensive knowledge of the morphometry and relationship of superior orbital fissure are vital for an accurate diagnosis and management of local pathology as well as knowledge of morphometry and relationship of SOF is important for neurosurgeons, radiologists, ophthalmologists and anatomists.

Material and methods: The study was conducted on 30 dry skulls and computed tomography (CT) scans of 30 adult patients. Parameters observed in the present study include SOF length and width, distance from foramen rotundum to SOF and distance from the apex of petrous temporal bone to SOF.

Results: The mean length of SOF in dry skull was $16.18 \mathrm{~mm}$ on the left side and $15.93 \mathrm{~mm}$ on the right side. The mean length of SOF in CT scan was $10.92 \mathrm{~mm}$ on the left side and $10.90 \mathrm{~mm}$ on the right side. Similarly, the mean width in dry skull and CT scan was $8.44 \mathrm{~mm}$ and $6.13 \mathrm{~mm}$ on the left side, respectively. The mean width in dry skull and CT scan was $8.64 \mathrm{~mm}$ and $6.14 \mathrm{~mm}$ on the right side, respectively. The distance of SOF to the apex of petrous temporal bone in dry skull was $21.86 \mathrm{~mm}$ on the left side and $22.22 \mathrm{~mm}$ on the right side, while in CT it was $25.15 \mathrm{~mm}$ on the left side and $25.07 \mathrm{~mm}$ on the right side. The distance of SOF to foramen rotundum was $4.50 \mathrm{~mm}$ on the left side and $4.91 \mathrm{~mm}$ on the right side in dry skull, while in CT scan it was $2.73 \mathrm{~mm}$ on the left side and $2.79 \mathrm{~mm}$ on the right side.

Discussion: Most of parameters did not shows any significant differences between the left and right side in both dry skull and CT scan, except the distance of SOF to foramen rotundum in dry skull, where the right side distance was significantly higher.

Conclusion: The above mentioned parameters will help ophthalmologists, neurosurgeons and radiologists during surgical procedures.
\end{abstract}

Keywords: superior orbital fissure, morphometry, radiological, dry skull.

\footnotetext{
Address for correspondence:

Dr. Ajay Kumar Patel, Assistant Professor

email:dr.ajaykumar2008@gmail.com
} 


\section{INTRODUCTION}

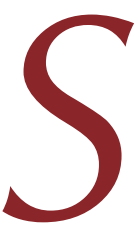
uperior orbital fissure (SOF) is a very important region because important nerves and vessels of the orbit pass through these foramina $(1,2)$. It is situated between the lesser wing (above) and greater wing (below) of the sphenoid bone and the medial margin is bounded by the body of the sphenoid bone. It separates the roof and lateral wall of orbit posteriorly. Superior orbital fissure connects the orbit to the middle cranial fossa. Comprehensive knowledge of its morphometry and relationship with nearby important structures are vital for an accurate diagnosis and management of local pathology (3). For radiologists and neurosurgeons, the knowledge of morphometry and relation of SOF is very important. Most of previous studies regarding SOF are either bony or cadaveric studies.

By conducting the present study, we can make comprehensive morphometric and morphological analysis of superior orbital fissure in dry bone as well as CT scan. Figure 1 shows the contents of SOF and its relation with each other and contents of optic foramen.

\section{MATERIALS AND METHODS}

\section{(} ur study was carried out in the Department of Anatomy in conjunction with the Department of Radiodiagnosis, Vardhman Mahavir Medical College \& Safdarjung Hospital, New Delhi, India. It was performed in 30 dry adult human skulls and CT scans of 30 adult patients.

Thirty dry adult human skulls with normal gross morphology of unknown age and sex were used in the study. Also, CT scans of 30 adult patients were examined. All patients underwent a scanning of head and/or paranasal sinuses for various symptoms. Informed consent was obtained from patients before performing the scan. In the study group there were 19 males and 11 females aged between 19 to 65 years old. We included in the study only patients who did not have any congenital deformity or history of trauma.

The following parameters were observed in both dry skulls and CT scans of patients: SOF length; SOF width; distance of medial end SOF to the apex of petrous temporal bone; and distance of SOF medial end to foramen rotundum.
In dry skulls, measurements were made intracranially with help of digital Vernier callipers of $0.1 \mathrm{~mm}$ sensitivity. For the radiological observation, high resolution unenhanced CT scans of the skull base were performed on a 40 slice Philips Brilliance 190 P scanner. Data were acquired helically in a plane parallel to the infraorbitomeatal line. Thin sections (1-1.5 mm) in axial and coronal planes were reconstructed using high resolution matrix and bone algorithm.

Data obtained from the present study were analysed as per standardized methods. The analysis was performed by applying paired $t$ test for comparison of morphometric parameters of the right and left sides, and $p \leq 0.05$ was considered statistically significant. Mean values, standard deviation (SD) and range were taken into consideration in the statistical analysis.

\section{RESULTS}

\section{natomical features \\ Superior orbital fissure was retort shaped in all examined dry skulls and CT scans. The mar-}

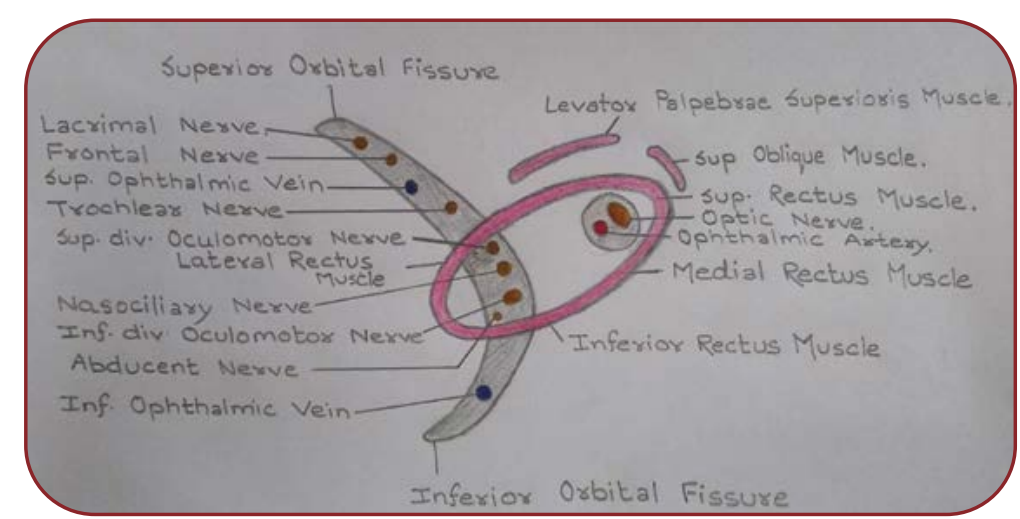

FIGURE 1. Contents of superior orbital fissure and its relation with optic foramen (belonging to the right side)

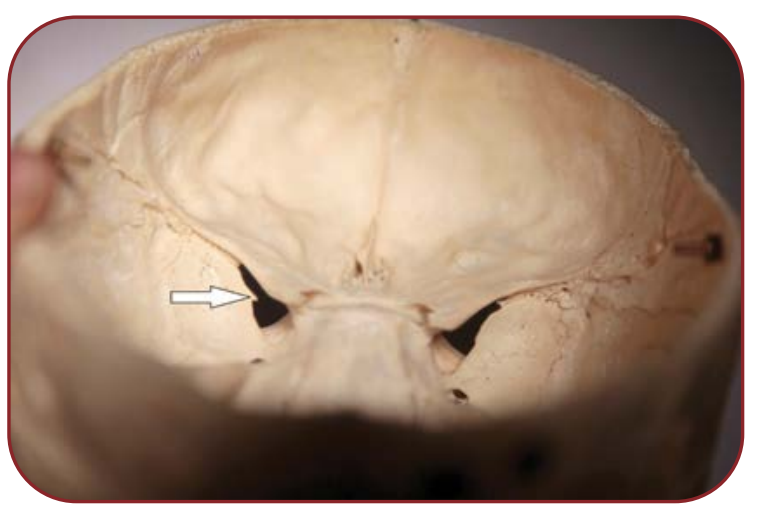

FIGURE 2. Bony spicule on the inferior margin of left sided superior orbital fissure (marked by arrow) - endocranial view 


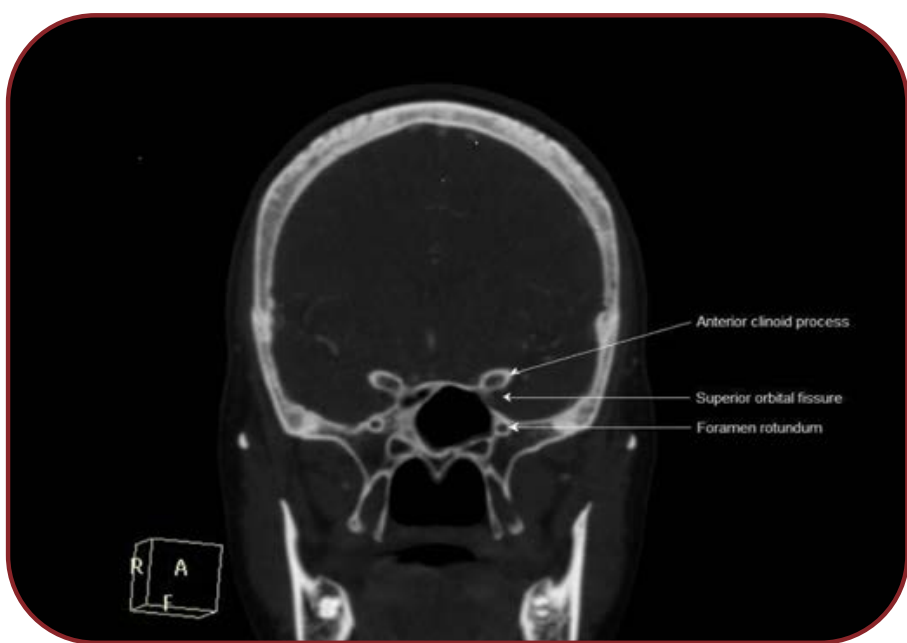

FIGURE 3. Superior orbital fissure, foramen rotundum and anterior clinoid process

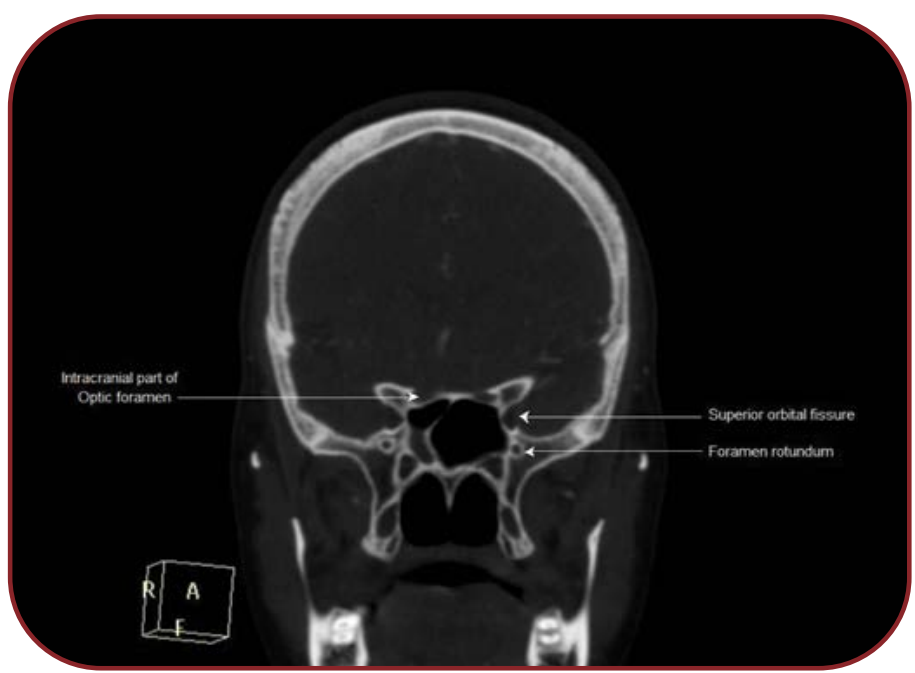

FIGURE 4. Superior orbital fissure, foramen rotundum and intracranial part of optic foramen

gins of SOF were found to be regular in the majority of examined dry skulls. However, a tubercle was noticed on SOF lower margin unilaterally on the left side in one skull. There was no other unusual morphological features of SOF in the dry skulls. No unusual morphological features of SOF were visualized in any of the explored CT scans. The anatomical features of SOF are illustrated in Figure 2, while SOF, foramen rotundum, optic foramen and clinoid process are showed in Figures 3 and 4.

\section{Morphometric evaluation}

The morphometric observations of SOF are summarized in Tables 1 and 2.

\section{DISCUSSION}

The superior orbital fissure connects the middle cranial fossa with the orbit. In the present study, SOF was found to be retort shaped in all examined dry skulls and CT scans of patients. No case exhibited the presence of a bony prominence dividing the fissure into medial and lateral parts. However, in one dry skull a bony spicule emanating from the inferior margin of the left SOF was observed. This is contrary to a previously reported observation according to which a bilateral symmetrical bony prominence projecting from the greater wing of the sphenoid was observed in seven out of $60 \mathrm{CT}$ scan reports of patients (4).

The mean length and width of SOF in dry skulls and CT scans that were measured in the current study did not show any statistically significant difference between the two sides. This is not consistent with an earlier study that reported an asymmetry in terms of SOF dimensions (4). However, the mean length of SOF was reported to be $20.05 \mathrm{~mm}$ in an earlier investigation (5) in dry skulls which is greater than the value of pre-

\begin{tabular}{|l|l|l|l|}
\hline \multirow{2}{*}{ Parameter } & \multicolumn{2}{|l|}{$\begin{array}{l}\text { Mean } \pm \text { SD (mm) (n) } \\
\text { Range }=\text { Max }- \text { Min }(\mathbf{m m})\end{array}$} & \multirow{2}{*}{ p value } \\
\cline { 2 - 3 } & Left (n=30) & Right (n=30) & \\
\hline \multirow{2}{*}{ Length } & $16.18 \pm 2.89$ & $15.93 \pm 3.41$ & 0.359 \\
& $(24.50-11.80)$ & $(24.00-10.40)$ & \\
\hline Width & $8.44 \pm 1.27$ & $8.64 \pm 1.42$ & 0.271 \\
& $(11.00-6.00)$ & $(11.00-5.50)$ & \\
\hline Distance of superior orbital fissure & $21.86 \pm 1.99$ & $22.22 \pm 1.58$ & 0.197 \\
to apex of petrous temporal bone & $(25.90-16.20)$ & $(28.20-20.00)$ & \\
\hline Superior orbital fissure to foramen & $4.50 \pm 0.96(30)$ & $4.91 \pm 1.03(30)$ & $0.032^{*}$ \\
rotundum & $(6.80-2.80)$ & $(7.00-2.70)$ & \\
\hline
\end{tabular}

TABLE 1. Morphometric observations of orbital fissure in dry skulls 


\begin{tabular}{|c|c|c|c|}
\hline \multirow[t]{2}{*}{ Parameter } & \multicolumn{2}{|c|}{$\begin{array}{l}\text { Mean } \pm \text { SD }(\mathrm{mm})(\mathrm{n}) \\
\text { Range }=\text { Max }- \text { Min }(\mathrm{mm})\end{array}$} & \multirow[t]{2}{*}{$p$ value } \\
\hline & Left $(n=30)$ & Right $(\mathrm{n}=30)$ & \\
\hline Length & $\begin{array}{l}10.92 \pm 1.25 \\
(14.20-8.90)\end{array}$ & $\begin{array}{l}10.90 \pm 1.20 \\
(13.40-7.90)\end{array}$ & 0.905 \\
\hline Width & $\begin{array}{l}6.13 \pm 1.18 \\
(8.10-4.00)\end{array}$ & $\begin{array}{l}6.14 \pm 0.95 \\
(7.40-3.20)\end{array}$ & 0.982 \\
\hline $\begin{array}{l}\text { Superior orbital fissure to apex } \\
\text { of petrous temporal bone }\end{array}$ & $\begin{array}{l}25.15 \pm 3.33 \\
(31.40-17.90)\end{array}$ & $\begin{array}{l}25.07 \pm 2.78 \\
(29.70-19.10)\end{array}$ & 0.822 \\
\hline $\begin{array}{l}\text { Superior orbital fissure to } \\
\text { foramen rotundum }\end{array}$ & $\begin{array}{l}2.73 \pm 0.65(30) \\
(3.80-1.30)\end{array}$ & $\begin{array}{l}2.79 \pm 0.77(30) \\
(4.80-1.60)\end{array}$ & 0.647 \\
\hline
\end{tabular}

TABLE 2. Morphometric observations of orbital fissure in CT scans

sent study. On the other hand, the value of mean width of SOF in CT scans of patients was reported to be $3.73 \mathrm{~mm}$ in a previous study (6) which is much less than the measurements of current study.

Further the mean distance of SOF to apex of petrous temporal bone as measured in dry skulls and CT scan of patients did not show any statistically significant difference between two sides.

Sinanoglu et al (7) observed SOF width and height through cone Beam Computed Tomography scan (CBCT) on 182 patients (101 females and 81 males). They found that SOF width was $4.58 \mathrm{~mm}$ and $4.72 \mathrm{~mm}$ on the right and left side, respectively, in men, and $3.82 \mathrm{~mm}$ and $3.92 \mathrm{~mm}$ on the right and left side, respectively, in women. The height of SOF was $2.92 \mathrm{~mm}$ and $2.98 \mathrm{~mm}$ in males, and $2.2 \mathrm{~mm}$ and $2.02 \mathrm{~mm}$ in females, on the right and left side, respectively. All parameters had lower values than those measured in the present study.

\section{CONCLUSION}

$\triangle$ natomical and morphometric observations of SOF will help ophthalmologists and neurosurgeons not only during surgical procedures but also for newer technique advancement. Anatomical and morphometric observations will also help radiologists in making an accurate diagnosis of any pathology related to structures near to SOF or involving the superior orbital fissure. These data also will also help in planning and performing the endoscopic endonasal extended approach of seller, suprasellar and parasellar pathology.

Conflicts of interest: none declared. Financial support: none declared.

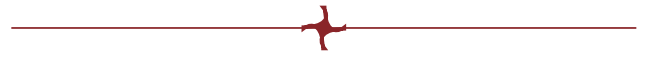

\section{$\boldsymbol{R}_{\text {fFerReNCES }}$}

1. Lang J. Skull Base and Related Structures: Atlas of Clinical Anatomy. Stuttgart, Schattauer, $2^{\text {nd }}$ edition, 2001, p 114.

2. Natori Y, Rhoton AL Jr. Microsurgical anatomy of superior orbital fissure. Neurosurgery 1995:36;762-775.

3. Gosava F, Kayalioglu G, Erturk M, Ozgur T. The superior orbital fissure and its contents. Surg Radiol Anat 1999;21:181-185

4. Burdan F, Umławska W,
Dworzański W, et al. Anatomical variances and dimensions of the superior orbital fissure and foramen ovale in adults.

Folia Morphol 2011;70:263-271.

5. Berlis A, Putz R, Schumacher M. Direct and CT measurements of canals and foramina of the skull base. Br J Radiol 1992;65:653-661.

6. Fujiwara T, Matsuda K, Kubo T, et al. Superior orbital fissure syndrome after repair of maxillary and naso-orbito-ethmoid fractures: a case study. J Plast Reconstr Aesthet Surg 2009;62:565-569.

7. Sinanoglu A, Orhan K, Kursun S, et al. Evaluation of optic canal and surrounding structure using cone beam computed tomography: Considerations for maxillofacial surgery. J Craniofac Surg 2016;27:1327-1330. 